\title{
Impact of Adding Midazolam to Bupivacaine $0.5 \%$ in Regional Spinal Anesthesia on Maternal Middle Cerebral Artery Velocimetry in Parturients with Severe Preeclampsia
}

\author{
Mina Maher Raouf ${ }^{*}$, Hany Kamal Mikhail1', Mohammad Ameen², Mohammed Awad Alsaeid ${ }^{3}$, \\ Samar Magdy ${ }^{1}$
}

${ }^{1}$ Department of Anesthesia and ICU, Faculty of Medicine, El Minia University, El Minia, Egypt

${ }^{2}$ Departement of Radiodiagnosis, Faculty of Medicine, El Minia University, El Minia, Egypt

${ }^{3}$ Department of Anesthesia and Pain, Faculty of Medicine, El Fayoum University, El Fayoum, Egypt

Email: ^drmina2015@gmail.com,hanykm@yahoo.com,samar.magdy41@yahoo.com,

mohammadamn@yahoo.com,drm.awad2008@yahoo.com

How to cite this paper: Raouf, M.M., Mikhail, H.K., Ameen, M., Alsaeid, M.A. and Magdy, S. (2020) Impact of Adding Midazolam to Bupivacaine $0.5 \%$ in Regional Spinal Anesthesia on Maternal Middle Cerebral Artery Velocimetry in Parturients with Severe Preeclampsia. Open Journal of Anesthesiology, 10, 232-246.

https://doi.org/10.4236/ojanes.2020.106021

Received: May 1, 2020

Accepted: June 14, 2020

Published: June 17, 2020

Copyright $\odot 2020$ by author(s) and Scientific Research Publishing Inc. This work is licensed under the Creative Commons Attribution International License (CC BY 4.0).

http://creativecommons.org/licenses/by/4.0/

\begin{abstract}
Severe preeclampsia is a challenging issue facing both intensivist and anesthetic team carrying both maternal and fetal morbidity and mortality. Termination of pregnancy after blood pressure control is the golden key in management. Cerebral complications due to diffuse cerebral vasospasm are most common and serious. Intrathecal midazolam with its gamma amino butyric action may antidote glutamate mediated sympathetic surge and decreasing cerebral vasospasm. Temporal view transcranial Doppler imaging maternal middle cerebral artery is used to examine blood flow indices namely pulsatility index and resistive index. One hundred ladies with severe preeclampsia scheduled for urgent caesarian section were recruited in 2 groups, both received $10 \mathrm{mg}$ bupivacaine $0.5 \%$, Midazolam group received $1 \mathrm{mg}$ midazolam and the other group received $0.2 \mathrm{ml}$ sterile saline $0.9 \% \mathrm{NaCl}$. All vascular indices were significantly better in midazolam group, less ICU stay.
\end{abstract}

\section{Keywords}

Severe Preeclampsia, Transcranial Doppler, Midazolam, Spinal Anesthesia

\section{Background}

Preeclampsia is a disorder of widespread vascular endothelial malfunction and 
vasospasm occurring after 20 weeks of pregnancy and can present as late as 4 - 6 weeks postpartum [1]. The incidence of preeclampsia in the United States is estimated to range from $2 \%$ to $6 \%$ in healthy, nulliparous women [2]. In developing nations, the incidence of the disease is reported to be $4 \%-18 \%$ [3], with hypertensive disorders being the second most common obstetric cause of stillbirths and early neonatal deaths in these countries [4].

Risk factors for preeclampsia include primigravida, diabetes mellitus, kidney disease, chronic hypertension, previous personal or family history of pre-eclampsia, maternal age more than 35 years, obesity, antiphospholipid antibody syndrome and multiple gestations [5].

Pre-eclampsia can be diagnosed through systolic blood pressure $\geq 140 \mathrm{~mm}$ $\mathrm{Hg}$ or diastolic $\geq 90 \mathrm{~mm} \mathrm{Hg}$ on two separate readings taken at least four to six hours apart after twenty weeks [6]. In a woman with essential hypertension beginning before twenty weeks gestational age, the diagnostic criteria include an increase in systolic blood pressure (SBP) by $\geq 30 \mathrm{mmHg}$ or an increase in diastolic blood pressure (DBP) $\geq 15 \mathrm{mmHg}$, also Proteinuria $\geq 3$ grams is considered a diagnostic tool. Cerebral vasospasm is a corner stone in endothelial failure due sympathetic surge. Most fatal complications are due to diffuse cerebral vasospasm [7].

The rationale for the administration of intrathecal midazolam focuses on the awareness that it is an agonist at the benzodiazepine binding site, a subunit of the pentameric gamma-aminobutyric acid ( $G A B A-A)$ receptor. The agonist occupancy of the benzodiazepine binding site enhances the activity of GABA at the GABA-A receptor that can antidote glutamate mediated sympathetic overwhelming accompanying severe preeclampsia [8].

Transcranial Doppler ultrasonography (TCD) is considered the sole noninvasive real-time neuroimaging modality for the evaluation of characteristics of blood flow in basal intracerebral vessels. TCD adds physiologic information to structural imaging. Additionally, TCD has been rapidly evolving from a simple, noninvasive diagnostic tool to an imaging modality with a broad spectrum of clinical applications [9].

\subsection{Primary Objective}

Does intrathecal midazolam can dampen vascular indices of maternal middle cerebral artery in ladies with severe preeclampsia?

\subsection{Secondary Objectives}

1) Incidence of mortality and morbidity.

2) Cerebrovascular complications (Intracranial hemorrhage ...).

\section{Methods}

This prospective randomized double-blind study was approved by the local ethics committee of the Faculty of Medicine, El Minia University, and registered at 
clinical trials under the number of (NCT04283110). It was adhered to the Declaration of Helsinki and involved 100 ladies recruited into two groups, 50 ladies each. Both groups received subarachnoid block with $10 \mathrm{mg}$ bupivacaine $0.5 \%$ plus $1 \mathrm{mg}$ of midazolam in midazolam group or $0.2 \mathrm{ml}$ sterile saline $0.9 \% \mathrm{NaCl}$ as a placebo for equi-volume injection. Exclusion criteria included refusal for regional anesthesia or any condition prohibit subarachnoid block as coagulopathy.

An informed consent has been obtained from all participants who were randomly and equally allocated into two groups through web-based randomizer (https://www.randomizer.org/). Double blind fashion was executed (neither the observer nor the parturients was aware of study design).

Diagnosis of severe preeclampsia was held by senior obstetric resident of charge at the emergency room (ER). Two cardinal criteria must be checked, noninvasive blood pressure (NIBP) $\geq 140 / 90 \mathrm{mmHg}$ (two readings 5 minutes apart), albuminuria $>+++$ by boiling method. Presentation by imminent symptoms as headache, blurring of vision and nausea, HELLP syndrome (hemolysis of RBCs, elevated liver enzymes and low platelets) (hemolysis of RBC evidenced by elevated indirect bilirubin and lactate dehydrogenase $>600 \mathrm{IU}$, platelet count $<100.000$, if two of the above mentioned criteria were found, diagnosis of severe preeclampsia was declared. Pelvic ultrasound was done to confirm fetal state to exclude any fetal compromise and clarify complications.

Immediately after diagnosis, admission to obstetric Intensive care unit, Two wide bore cannulae (20 gauge, ultramed, Belgium) were inserted, one for drugs and the other for emergency. Full monitoring tools were applied NIBP, Electrocardiography, pulse oximetry and urinary foley catheter (16 gauge) was inserted after vaginal sterilization with Povidone Iodine (7.5\%). Investigations were performed: complete blood picture, liver functions, renal functions (serum urea and serum creatinine). Loading dose of Magnesium Sulphate $\left(\mathrm{MgSO}_{4}\right)(1 \mathrm{gm} / 10 \mathrm{ml} \mathrm{amp}) 4 \mathrm{gm}$ on $200 \mathrm{ml}$ Ringer lactate over $20 \mathrm{~min}$ followed by a maintenance infusion of 1 to $2 \mathrm{~g} / \mathrm{h}$ by controlled infusion pump. Our target was to control MAP between $90-100 \mathrm{mmHg}$ over 45 minutes, during $\mathrm{MgSO}_{4}$ infusion, Meticulous monitoring for signs of $\mathrm{MgSO}_{4}$ toxicity (respiratory rate $<16$ cycles per min, loss of knee jerk reflex, urine output less than $0.5 \mathrm{ml} / \mathrm{kg} / \mathrm{h}$ ). Any sign of the above mentioned criteria mandated immediate stop infusion of $\mathrm{MgSO}_{4}$ at once and serum Magnesuim was checked. If MAP was $\geq 110 \mathrm{mmHg}$ despite of $\mathrm{MgSO}_{4}$ infusion, Nitroglycerin (Nitronal, 50 $\mathrm{mg} / 50 \mathrm{ml}$, Sunny pharmaceutical) in an incremental dose starting with $1 \mathrm{mic} / \mathrm{kg} / \mathrm{h}$, upper maximum dose was $10 \mathrm{mic} / \mathrm{kg}$. Our goal was to control of MAP gently to 80 - $100 \mathrm{mmHg}$. Before C.S, another pelvic U/S was performed to evaluate fetal state. Brain imaging (brain CT and MCA trans-cranial Doppler performed and the results were documented. Throughout this management, all resuscitative measures (endotracheal tube, Atropine and Adrenaline) were ready for any emergency beside continuous cardiotocography (CTG) to detect any pathological fetal deceleration. Transcranial Doppler probe (Toshiba aplio 500 with convex probe $2-5 \mathrm{mhz}$ ) rested on the temporal window (just above the zygomatic arch between eye \& ear). Ladies 
were positioned in a semi-recumbent position with a 15-degree left lateral tilt.

A transcranial Doppler probe with a $10 \mathrm{~mm}$ sample volume was used to insonate the M1 (first $2 \mathrm{~cm}$ of the middle cerebral artery) portion of the middle cerebral artery by means of the transtemporal approach then the mean flow velocity, pulsatility index and resistance index values were recorded.

\subsection{Data Collection}

Included haemodynamic data, urine output, serum urea and creatinine, dose and duration of nitroglycerine, pulsatility index, resistive index, mean flow velocity and incidence of complications.

\subsection{Statistical Analysis}

We have determined a significant difference in the values of pulsatility index and resistive index by using the power of $80 \%$ and a significance level of $5 \%$, and accordingly sample size was determined to be 50 participants in each group. Collected data were firstly assessed by Kolmogorov-Smirnov for the normality, and were presented as a number, percentage, mean $\pm \mathrm{SD}$ or median (range). Chi-square test and Fisher Exact test were used to compare qualitative variables. Continuous variables were compared with t-test (Parametric data) or Mann-Whitney U test (Non-parametric data). A two-tailed $\mathrm{P}<0.05$ was considered statistically significant. P-value considered statistically significant when $\mathrm{P}$ $<0.05$. Data entry and data analysis were done using SPSS version 19 (Statistical Package for Social Science.

\section{Results}

\section{Parameters Assessed}

Table 1 shows the demographic data (age) of the parturients. The 100 participants were equally randomized between the two groups as shown in the CONSORT flow-chart (Figure 1), and they were comparable regarding their demographic details with insignificant differences in between.

Table 2 showed Changes in systolic blood pressure (SBP) in studied groups: Regarding changes in SBP, there was a statistically significant difference between the two groups immediately after induction, $5 \mathrm{~min}, 10 \mathrm{~min}$ after induction, after delivery of placenta, $20 \mathrm{~min}, 30 \mathrm{~min}$ of operation and all values during first $24 \mathrm{~h}$ postoperatively. Intragroup comparison showed significant statistical difference between pre induction values and all intra and postoperative values in both groups. Decline in SBP was steady and gentle in (M) group while it was sharp in (C) group. Rebound systolic hypertension was more evident in (C) group rather

Table 1. Age in the studied groups.

\begin{tabular}{cccc}
\hline Age in years & Midazolam group $(\mathrm{N}=50)$ & Control group $(\mathrm{N}=\mathbf{5 0})$ & P-value \\
\hline Mean \pm SD & $32.1 \pm 5.5$ & $30.5 \pm 6.9$ & 0.066 \\
\hline
\end{tabular}

SD: standard deviation; Analysis of quantitative data by independent sample t-test. 


\section{CONSORT 2010 Flow Diagram}

\section{Enrollment}

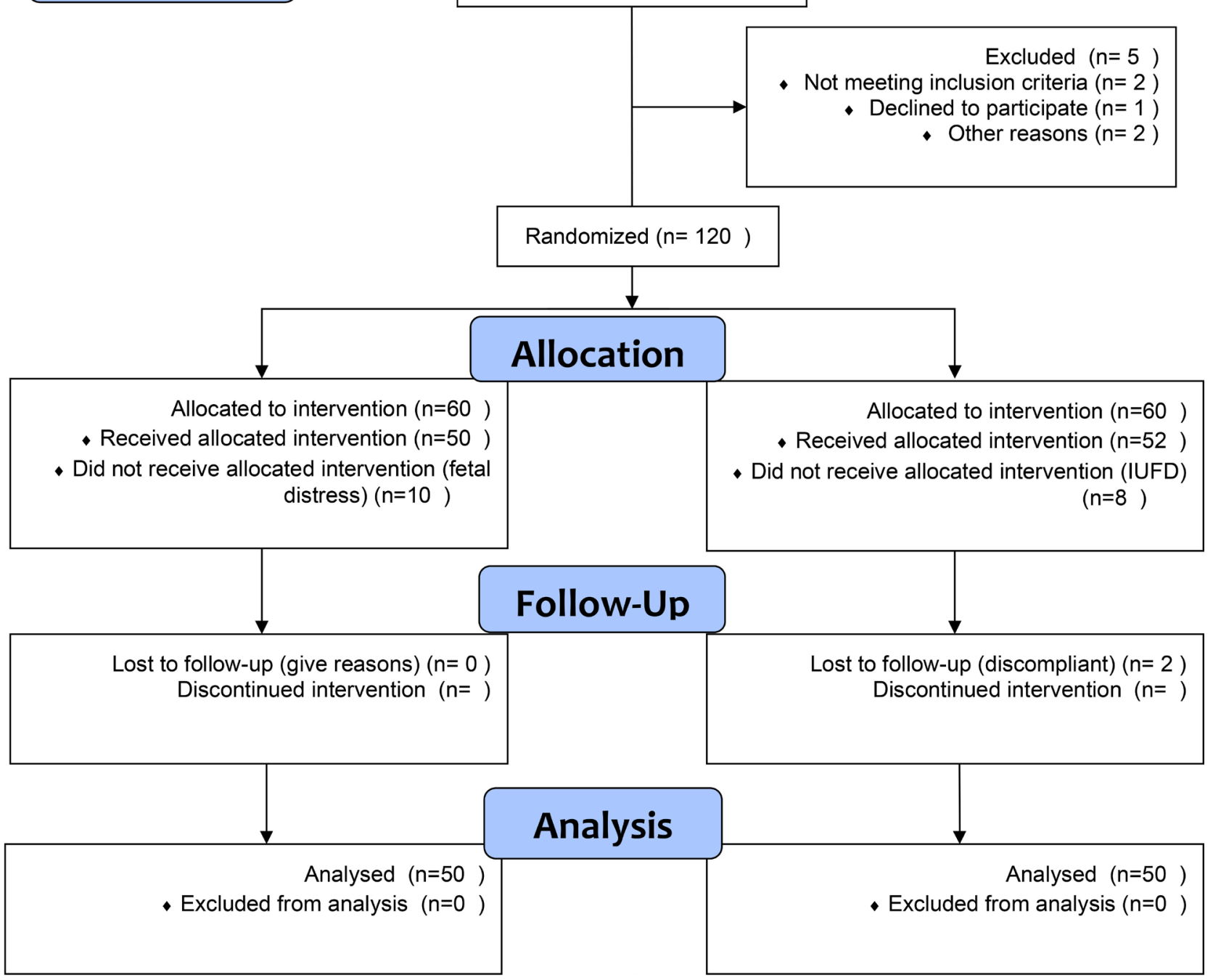

Figure 1. CONSORT flow chart.

than (M) group.

Table 3 shows Changes in diastolic blood pressure $(\mathrm{mmHg})$ in studied groups: Regarding changes in DBP among the studied groups pre, intra and post operatively were statistically significant difference between the two groups, 5 min, 10 min after induction, after delivery of placenta, one h, four hs, six hs, 12 hs, 18 hs and $24 \mathrm{~h}$ postoperatively.

Intragroup comparison showed significant statistically differences between pre induction values and all intra and postoperative values in both groups.

DBP decreased gently in (M) group but it showed sharp decrease in the (C) group with noticeable rebound hypertension occurred postoperatively.

Table 4 of nitroglycerine dose, Post operatively, 24 cases in (C) group mandated use of nitroglycerine to control postoperative rise in blood pressure with 
Table 2. Systolic blood pressure ( $\mathrm{mmHg}$ ) among studied groups.

\begin{tabular}{|c|c|c|c|}
\hline & $\begin{array}{c}\text { Midazolam } \\
\text { group }(N=50)\end{array}$ & $\begin{array}{l}\text { Control group } \\
\quad(\mathrm{N}=50)\end{array}$ & \multirow[t]{2}{*}{ P-value } \\
\hline & Mean \pm SD & Mean \pm SD & \\
\hline Basal (preoperative) & $160.6 \pm 13.3^{\#}$ & $164.07 \pm 17.4^{\#}$ & 0.264 \\
\hline Before induction & $148.6 \pm 7.0^{\#}$ & $150.7 \pm 10.7^{\#}$ & 0.230 \\
\hline After induction & $134.4 \pm 8.1^{\#}$ & $129.4 \pm 14.05^{\#}$ & $0.032^{*}$ \\
\hline 5 minutes & $124.4 \pm 11.6^{\#}$ & $116.07 \pm 20^{\#}$ & $0.012^{*}$ \\
\hline 10 minutes & $120.9 \pm 10.9^{\#}$ & $111.7 \pm 18.7^{\#}$ & $0.004^{*}$ \\
\hline After delivery of placenta & $116.2 \pm 10.4^{\#}$ & $107.4 \pm 15.9^{\#}$ & $0.002^{*}$ \\
\hline 10 minutes & $118.0 \pm 9.03^{\#}$ & $116.4 \pm 16.9^{\#}$ & 0.574 \\
\hline 20 minutes & $120.0 \pm 8.08^{\#}$ & $125.09 \pm 15.6^{\#}$ & $0.043^{*}$ \\
\hline 30 minutes & $120.6 \pm 7.9^{\#}$ & $127.4 \pm 16.1^{\#}$ & $0.008^{*}$ \\
\hline 10 minutes Postoperative & $127.8 \pm 12.0^{\#}$ & $135.8 \pm 15.6^{\#}$ & $0.004^{*}$ \\
\hline 30 minutes Postoperative & $130.6 \pm 12.5^{\#}$ & $138.03 \pm 14.6^{\#}$ & $0.007^{\star}$ \\
\hline One hour Postoperative & $129.4 \pm 12.5^{\#}$ & $138.8 \pm 13.6^{\#}$ & $<0.001^{*}$ \\
\hline Four hours Postoperative & $133.0 \pm 12.4^{\#}$ & $144.9 \pm 14.8^{\#}$ & $<0.001^{*}$ \\
\hline Six hours Postoperative & $134.4 \pm 14.02^{\#}$ & $148.4 \pm 14.7^{\#}$ & $<0.001^{*}$ \\
\hline Twelve hours Postoperative & $129.1 \pm 27.4^{\#}$ & $148.8 \pm 14.7^{\#}$ & $<0.001^{*}$ \\
\hline Eighteen hours Postoperative & $134.6 \pm 15.5^{\#}$ & $145.8 \pm 14.8^{\#}$ & $<0.001^{\star}$ \\
\hline Twenty-four hours Postoperative & $131.8 \pm 15.3^{\#}$ & $146.2 \pm 16.1^{\#}$ & $<0.001^{*}$ \\
\hline
\end{tabular}

Analysis of quantitative data by independent sample t-test; *: significant difference between two studied groups at $<0.05$.

Table 3. Diastolic blood pressure among studied groups.

\begin{tabular}{|c|c|c|c|}
\hline & $\begin{array}{c}\text { Midazolam } \\
\text { group }(\mathrm{N}=50)\end{array}$ & $\begin{array}{l}\text { Control group } \\
\qquad(\mathrm{N}=50)\end{array}$ & \multirow[t]{2}{*}{$P$-value } \\
\hline & Mean \pm SD & Mean \pm SD & \\
\hline Basal (preoperative) & $97.4 \pm 5.9^{\#}$ & $98.2 \pm 7.4^{\#}$ & 0.535 \\
\hline Before induction & $93.8 \pm 5.6^{\#}$ & $92.9 \pm 7.01^{\#}$ & 0.501 \\
\hline After induction & $85.4 \pm 8.3$ & $83.3 \pm 9.3^{\#}$ & 0.244 \\
\hline 5 minutes & $84.2 \pm 11.9^{\#}$ & $74.5 \pm 16.4^{\#}$ & $0.001^{*}$ \\
\hline 10 minutes & $78.6 \pm 10.1^{\#}$ & $70.5 \pm 13.7^{*}$ & $0.001^{*}$ \\
\hline After delivery of placenta & $76.4 \pm 10.05^{\#}$ & $68.2 \pm 11.08^{\#}$ & $<0.001^{*}$ \\
\hline 10 minutes & $77.6 \pm 8.9^{\#}$ & $73.9 \pm 11.5^{\#}$ & 0.076 \\
\hline 20 minutes & $79.2 \pm 8.04^{\#}$ & $81.1 \pm 9.7^{\sharp}$ & 0.269 \\
\hline 30 minutes & $79.2 \pm 8.2^{\#}$ & $81.7 \pm 9.3^{\#}$ & 0.147 \\
\hline 10 minutes Postoperative & $84 \pm 7.5^{\#}$ & $85.4 \pm 10.2^{\#}$ & 0.409 \\
\hline 30 minutes Postoperative & $84 \pm 7.8^{\#}$ & $85.8 \pm 8.7^{\#}$ & 0.258 \\
\hline
\end{tabular}


Continued

\begin{tabular}{cccc}
\hline One hour Postoperative & $84.2 \pm 8.8^{\#}$ & $89.02 \pm 8.06^{\#}$ & $0.005^{\star}$ \\
Four hours Postoperative & $85.6 \pm 8.6^{\#}$ & $91.5 \pm 8.5^{\#}$ & $0.001^{\star}$ \\
Six hours Postoperative & $88.3 \pm 9.3^{\#}$ & $92.1 \pm 9.2^{\#}$ & $0.044^{\star}$ \\
Twelve hours Postoperative & $87.1 \pm 8.5^{\#}$ & $93.7 \pm 11.9^{\#}$ & $0.002^{\star}$ \\
Eighteen hours Postoperative & $85.8 \pm 8.8^{\#}$ & $91.9 \pm 7.2^{\#}$ & $<0.001^{\star}$ \\
Twenty-four hours Postoperative & $86 \pm 10.1^{\#}$ & $91.3 \pm 7.7^{\#}$ & $0.003^{\star}$ \\
\hline
\end{tabular}

Analysis of quantitative data by independent sample t-test; ${ }^{*}$ significant difference between two studied groups at $<0.05$; " significant difference inside the same group.

Table 4. Dose of nitroglycerine intra and postoperative.

\begin{tabular}{cccc}
\hline $\mathrm{ml} / \mathrm{min}$ & $\begin{array}{c}\text { Midazolam group } \\
(\mathrm{N}=\mathbf{5 0})\end{array}$ & $\begin{array}{c}\text { Control group } \\
(\mathrm{N}=\mathbf{5 0})\end{array}$ & \multirow{2}{*}{ P-value } \\
\cline { 2 - 3 } & Mean $\pm \mathrm{SD}$ & Mean $\pm \mathrm{SD}$ & \\
\hline Intraoperative & $198 \pm 93$ & $160 \pm 104$ & 0.643 \\
Postoperative & $2764 \pm 1007$ & $3283 \pm 1503$ & $0.047^{\star}$ \\
\hline
\end{tabular}

Analysis of quantitative data by independent sample t-test.

mean \pm SD $3024 \pm 1855.1 \mathrm{mic} / \mathrm{kg}$ and total duration $754 \mathrm{hs}$ (32 days nearly) while in (M) group, statistically less number of cases (7) and less incremental dose(mean \pm SD $2013 \pm 1210.4 \mathrm{mic}$ ) and short duration (174 hours, about 8 days). There was a significant difference between the studied groups regarding (Number of cases, total dose \& total duration of nitroglycerine infusion with ( $\mathrm{P}$ value $=0.004)$ ).

Table 5 shows mean serum creatinine among studied groups. With no statistically significant difference between studied groups as regard serum creatinine.

Table 6 shows fetal APFAR score. There is no significant difference among studied groups regarding APGAR score.

A: activity, P: pulse, G: grimace, A: appearance, R: respiration.

Table 7 represents complications among studied groups.

Table 8 represents pulsatility index among studied groups, There was a significant difference between studied groups at $6 \mathrm{~h}$ and $24 \mathrm{~h}$ postoperatively with ( $\mathrm{P}$ value $<0.001,<0.001)$ for the Rt side and $(0.003$ and, 0.004$)$ for the $\mathrm{Lt}$ side.

There was also a significant difference between the PI values among (M) group at $6 \mathrm{~h}$ and $24 \mathrm{~h}$ compared with basal value on both sides.

Table 9 of MFV among studied groups, there was no significant difference in between or inside studied groups by comparing the MFV.

Table 10, by comparing the RI values among studied groups, there was a statistical significant difference between baseline values and values at 6 and 24 hours postpartum on both sides.

Table 11 points to resistive vascular index of maternal middle cerebral artery revealing significant decrease in resistive vascular index of both right and left sides at 6 and 24 hours postpartum. 
Table 5. Representing serum urea pre and postoperative.

\begin{tabular}{cccc}
\hline Mmol/L & $\begin{array}{c}\text { Midazolam } \\
\text { group }(\mathbf{N}=\mathbf{5 0})\end{array}$ & $\begin{array}{c}\text { Control group } \\
(\mathbf{N}=\mathbf{5 0})\end{array}$ & \multirow{2}{*}{ P-value } \\
\cline { 2 - 3 } & Mean \pm SD & Mean \pm SD & \\
\hline Basal (preoperative) & $26.1 \pm 8.8$ & $30.8 \pm 18.6$ & 0.077 \\
Twenty-four hours Postoperative & $23.9 \pm 8.9$ & $30.6 \pm 15.4$ & $0.009^{\star}$ \\
Forty-eight hours Postoperative & $26.2 \pm 7.7$ & $31.03 \pm 17.05$ & 0.070 \\
\hline
\end{tabular}

Table 6. Representing serum creatinine pre and postoperative.

\begin{tabular}{cccc}
\hline Mg/dl & $\begin{array}{c}\text { Midazolam } \\
\text { group }(\mathrm{N}=50)\end{array}$ & $\begin{array}{c}\text { Control group } \\
(\mathrm{N}=50)\end{array}$ & P-value \\
\cline { 2 - 3 } & Mean \pm SD & Mean \pm SD & \\
Basal (preoperative) & $0.82 \pm 0.18$ & $0.85 \pm 0.29$ & 0.617 \\
Twenty-four hours Postoperative & $0.84 \pm 0.17$ & $0.89 \pm 0.42$ & 0.456 \\
Forty-eight hours Postoperative & $0.82 \pm 0.17$ & $0.97 \pm 0.60$ & 0.089 \\
\hline
\end{tabular}

Table 7. Representing fetal APGAR score.

\begin{tabular}{cccc}
\hline & $\begin{array}{c}\text { Midazolam group } \\
(\mathrm{N}=\mathbf{5 0})\end{array}$ & $\begin{array}{c}\text { Control group } \\
(\mathrm{N}=\mathbf{5 0})\end{array}$ & P-value \\
\hline Mean $\pm \mathrm{SD}$ & $8 \pm 0$ & $8 \pm 0$ & 1.000 \\
\hline
\end{tabular}

Table 8. Representing complications.

\begin{tabular}{|c|c|c|c|c|}
\hline & & $\begin{array}{l}\text { Midazolam group } \\
\qquad(\mathrm{N}=50)\end{array}$ & $\begin{array}{l}\text { Control group } \\
\qquad(\mathrm{N}=50)\end{array}$ & P-value \\
\hline \multicolumn{5}{|c|}{ Eclampsia } \\
\hline & Yes & $9(18 \%)$ & $17(34 \%)$ & \multirow{4}{*}{$0.005^{\star}$} \\
\hline & 1 seizure & $2(4 \%)$ & $3(6 \%)$ & \\
\hline & 2 seizures & $4(8 \%)$ & $12(24 \%)$ & \\
\hline & 3 seizures & $3(6 \%)$ & $2(4 \%)$ & \\
\hline \multicolumn{5}{|l|}{ PRESS } \\
\hline & Yes & $8(16 \%)$ & $22(44 \%)$ & $0.004^{*}$ \\
\hline \multicolumn{5}{|c|}{ Intracranial hemorrhage } \\
\hline & Yes & $0(0 \%)$ & $1(2 \%)$ & 0.315 \\
\hline \multicolumn{5}{|c|}{ Acute renal failure } \\
\hline & Yes & $0(0 \%)$ & $1(2 \%)$ & 0.315 \\
\hline \multicolumn{5}{|c|}{ Acute renal injury } \\
\hline & Yes & $0(0 \%)$ & $1(2 \%)$ & 0.315 \\
\hline \multicolumn{5}{|c|}{ Liver cell } \\
\hline Failure & YES & $0(0 \%)$ & $1(2 \%)$ & 0.315 \\
\hline \multicolumn{5}{|c|}{ Pulmonary edema } \\
\hline & Yes & $1(2 \%)$ & $2(4 \%)$ & 0.559 \\
\hline
\end{tabular}




\section{Continued}

\begin{tabular}{|c|c|c|c|c|}
\hline \multicolumn{5}{|c|}{ Need for intubation } \\
\hline & Yes & $1(2 \%)$ & $3(6 \%)$ & 0.309 \\
\hline \multicolumn{5}{|c|}{ Weaning } \\
\hline & Yes & $1(2 \%)$ & $0(0 \%)$ & 0.317 \\
\hline \multicolumn{5}{|c|}{ Mortality } \\
\hline & Yes & $0(0 \%)$ & $3(6 \%)$ & 0.080 \\
\hline & & $\begin{array}{l}\text { Midazolam group } \\
\qquad(\mathrm{N}=50)\end{array}$ & $\begin{array}{l}\text { Control group } \\
\quad(\mathrm{N}=50)\end{array}$ & P-value \\
\hline & & Mean \pm SD & Mean \pm SD & \\
\hline \multirow[t]{3}{*}{ RT } & Basal & $1.17 \pm 0.56$ & $1.36 \pm 0.64$ & 0.121 \\
\hline & Six hours & $0.90 \pm 0.60^{\#}$ & $1.39 \pm 0.73$ & $<0.001^{\star}$ \\
\hline & Twenty-four hours & $0.77 \pm 0.46^{\#}$ & $1.29 \pm 0.67$ & $<0.001^{*}$ \\
\hline \multirow[t]{3}{*}{ LT } & Basal & $1.80 \pm 2.6$ & $1.23 \pm 0.67$ & 0.147 \\
\hline & Six hours & $0.83 \pm 0.56^{\#}$ & $1.23 \pm 0.74$ & $0.003^{*}$ \\
\hline & Twenty-four hours & $0.79 \pm 0.47^{\#}$ & $1.12 \pm 0.63$ & $0.004^{*}$ \\
\hline
\end{tabular}

Table 10. Representing mean flow velocity.

\begin{tabular}{ccccc}
\hline & & $\begin{array}{c}\text { Midazolam group } \\
(\mathrm{N}=50)\end{array}$ & $\begin{array}{c}\text { Control group } \\
(\mathrm{N}=50)\end{array}$ & \multirow{2}{*}{ P-value } \\
\cline { 3 - 4 } & & Mean $\pm \mathrm{SD}$ & Mean $\pm \mathrm{SD}$ & \\
\hline \multirow{2}{*}{ RT } & Basal & $65.5 \pm 17.8$ & $61.9 \pm 25.3$ & 0.411 \\
& Six hours & $64.7 \pm 20.8$ & $61.6 \pm 23.5$ & 0.476 \\
& Twenty-four hours & $65.8 \pm 18.7$ & $62.7 \pm 20.1$ & 0.430 \\
& BT & $61.8 \pm 19.9$ & $65.7 \pm 20.2$ & 0.326 \\
& Six hours & $66.3 \pm 21.4$ & $62.8 \pm 19.5$ & 0.395 \\
& Twenty-four hours & $64.4 \pm 22.2$ & $61.4 \pm 20.5$ & 0.482 \\
\hline
\end{tabular}

Table 11. Shows resistive index.

\begin{tabular}{|c|c|c|c|c|}
\hline & & $\begin{array}{l}\text { Midazolam group } \\
\qquad(\mathrm{N}=50)\end{array}$ & $\begin{array}{l}\text { Control group } \\
(\mathrm{N}=50)\end{array}$ & P-value \\
\hline & & Mean \pm SD & Mean $\pm S D$ & \\
\hline \multirow[t]{3}{*}{ RT } & Basal & $0.69 \pm 0.30$ & $0.79 \pm 0.34$ & 0.127 \\
\hline & Six hours & $0.56 \pm 0.26^{\#}$ & $0.81 \pm 0.33$ & $<0.001^{\star}$ \\
\hline & Twenty-four hours & $0.51 \pm 0.19^{\#}$ & $0.74 \pm 0.30$ & $<0.001^{\star}$ \\
\hline \multirow[t]{3}{*}{ LT } & Basal & $0.76 \pm 0.23$ & $0.67 \pm 0.23$ & 0.057 \\
\hline & Six hours & $0.50 \pm 0.21^{\#}$ & $0.69 \pm 0.27$ & $<0.001^{\star}$ \\
\hline & Twenty-four hours & $0.49 \pm 0.24^{\#}$ & $0.68 \pm 0.35$ & $0.003^{*}$ \\
\hline
\end{tabular}




\section{Discussion}

Preeclampsia is a challenging obstetric emergency facing both anesthetists and intensivists. Preeclampsia confers high incidence of maternal and fetal morbidity. During the period of the current study, the incidence of severe preeclampsia in our hospital was $15.4 \%$ (352 preeclamptic ladies out of 2282 presented in the ER for emergency termination of pregnancy). Severe preeclampsia is the most common cause of urgent C.S and admission to obstetric ICU in our center.

The middle cerebral artery is the largest branch of the internal carotid artery carrying $75 \%$ of total CBF supplies a portion of the frontal lobe and the lateral surface of the temporal and parietal lobes. Minor changes in blood flow velocity in MCA correlates well with global CBF (Joris et al., 2018).

Transcranial Doppler is the only noninvasive real-time neuroimaging modality for the evaluation of characteristics of blood flow in intracranial vessels that adds physiologic information to structural imaging. TCD can provide information about vascular stenosis and occlusion, the hemodynamic status of the cerebral circulation, and real-time monitoring of vascular indices. TCD is useful for detecting increased intracranial pressure (Tsivgoulis et al., 2009).

In the current study, TCD assess the proximal portion of the MCA through temporal window, this examined segment contains two types of receptors; Serotonin (5HT) and Dopamine receptors(D) that are not affected by the acetylcholine, so free from effect of $\mathrm{MgSO}_{4}$ on these receptors (Purkayastha and Sorond, 2012). This clarifies any change in the values of resistive indices is exclusively explained by intrathecal midazolam effect.

Control (C) Group showed a noticeable decline in both systolic and diastolic blood pressure either after subarachnoid block or after placental delivery while postoperatively, there was a rebound systolic and diastolic hypertension in the same group. Consequently, more number of cases (24) were in need to higher incremental doses of nitroglycerine (mean \pm SD $(3024 \pm 1855.01 \mathrm{mic} / \mathrm{kg})$ ) and lasting for longer duration (32 days). In ( $\mathrm{M}$ ) group, we noticed that decline was steady and gentle in both systolic and diastolic blood pressure after subarachnoid block and placental delivery with minimal rebound hypertension postoperatively, less number of ladies (7) were in need of incremental doses of nitroglycerine (mean \pm SD2013 \pm 1210.4 ) with less duration ( 8 days explained by the fact that midazolam has a bupivacaine-sparing effect and thus causes gradual sympathectomy. Pharmacokinetics of midazolam points to its preferential diffusion to lamina II in posterior horn cell in grey matter of spinal cord away from the lateral horn cells hosting sympathetic nuclei thus preserve sympathetic tone to some extent (Shadangi et al., 2011).

In agreement of our study, Sanwaletal, 2013 studied the bupivacaine sparing effect of intrathecal midazolam in sub-arachnoid block for cesarean section and discovered that the hypotensive episodes was greater in control group while all Midazolam groups (1 mg, $1.5 \mathrm{mg}$ and $2 \mathrm{mg}$ ) showed steep values of SBP and DBP (less episodes of hypotension). 
Neuronal complications of severe preeclampsia (eclampsia, PRESS and intracranial hemorrhage) are the most common cause of maternal and fetal morbidity and mortality. Incidence of neuronal complications was higher in (C) group, 40 cases) while only 9 cases in (M) group.

Intracranial haemorrhage was in focus in one lady in (C) group. She experienced both systolic and diastolic hypertension, early nitroglycerin infusion started immediately after ICU admission for 24 hours postpartum. The lady developed 2 attacks of eclamptic fits during this period. Mechanical ventilation was initiated immediately after first fit to protect airway and prevention of aspiration pneumonia. Brain CT revealed massive ltparieto-occipital hematoma.

Acute kidney injury in sever preeclampsia is the second cause for maternal and fetal morbidity and mortality. Diffuse release of vasospastic materials (endothelin, serotonin, noradrenaline and abruptio placenta) are the main stay for both direct and indirect renal injury.

Urine output, serum urea and serum creatinine were higher in (C) group, while in (M) group it showed less amount of urine output with lower serum urea and creatinine. This can be explained as there were 2 cases in (C) group with acute kidney injury managed by forced diuresis. (M) group showed significant lower incidence than $(\mathrm{C})$ group. For renal impairment at (C) group; one case (2\%) had acute renal injury with subsequent elevation in the renal function responded to fluid challenge and forced diuresis. Also there was a case of acute renal failure was refractory to fluid challenge and frusemide infusion, was elicited for hemodialysis.

In agreement with our study, Goplani et al, 2008 reported a study between January 2004 and May 2006, 772 patients with ARF were admitted at the Institute Of Kidney Diseases and Research Centre and Institute Of Transplantation Sciences. A total of 92 patients with ARF were pregnant. Of these, 22 patients had the evidence of renal disease prior to pregnancy and were excluded; hence, 70 patients with pregnancy-related ARF were studied.

Pregnant women who were healthy previously and had developed ARF were diagnosed in oliguria (Urine output $<400 \mathrm{ml} / \mathrm{d}$ ) and for mounting azotemia (Serum creatinine $>2 \mathrm{mg} \%$ ). The incidence of ARF due to pregnancy related hypertension was $10 \%$. A majority of the patients (97.14\%) underwent hemodialysis, while one died without dialysis; further, one patient underwent peritoneal dialysis due to hypotension and died later. Peritoneal dialysis was initially performed in 8 patients $(11.42 \%)$ due to initial hypotension, 7 patients among which improved and received hemodialysis later.

Impaction of sever preeclampsia on liver is evident. Increased hepatic vascular bed resistance, we noticed that serum ALT post operatively $24 \mathrm{~h}$ was significant in control group than in M group. ALT is more sensitive in cases of acute liver injury. This finding can be explained by more number of HELLP syndrome parturient preoperatively in control group. For liver impairment, in (C) group one case experienced acute fulminant hepatitis $24 \mathrm{~h}$ postpartum. This case was 
included in HELLP syndrome criteria (elevated ALT, AST more than 5 folds, Platelets $<100,000)$ secondary to vasospasm of the hepatic vascular bed. Patient responded to medical management (liver support, Vit k) patient was referred to tropical department with no mortality.

Regarding non cardiogenic pulmonary edema, two cases at (C) group were detected after $12 \mathrm{~h}$ postpartum, managed with forced dieresis (frusimide 0.2 - 2 $\mathrm{mg} / \mathrm{kg} / \mathrm{h}$ ). Two patient were mechanical ventilated after failure of force diuresis (RR $35 \mathrm{c} / \mathrm{m}, \mathrm{PH}<7.1$ and $\mathrm{Spo} 2<90 \%$ ). Both patients could not be weaned from mechanical ventilation, both parturient were mechanically ventilated for 3 days. At $(\mathrm{M})$ group one case with non cardiogenic pulmonary edema managed with mechanical ventilation and successfully weaned after $24 \mathrm{~h}$. In the all above mentioned cases echo cardiograph was done revealed normal left ventricular systolic function.

Mortality rate was higher in (C) group than (M) group. Three cases were enrolled in mortality, 2 parturients with non cardiogenic pulmonary edema and on case with $\mathrm{ICH}$. No mortality was detected in (M) group.

In a study carried out with Ghulmiyyah et al., 2012 mortality and morbidity related to preeclampsia were as the following: death $0-15$, aspiration pneumonia 2 - 10, pulmonaryedema 3 - 12, abruptio placentae 7 - 10, disseminated coagulopathy $7-20$, acute renal failure $5-10$, cardiopulmonary arrest $2-10$, liver failure $1-10$ where lower values were in developed countries and higher values were in developing countries.

Transcranial Doppler was very helpful in detection and prediction of incidence of eclampsia as there were a noticeable elevation in MCA resistive indices in (C) group rather than (M) group. Cerebral vasospasm as a component of the pathophysiology in eclamptic women has been consistently described with transcranial Doppler ultrasound. This is illustrated by elevated middle cerebral blood flow velocities and high resistive and pulsatility indices in patients with preeclampsia. Doppler indices in MCA have been shown to be significantly higher in preeclamptic women in control group as compared with that in preeclamptic women in midazolam group. Many of the agents used have potent vascular effects and may have caused cerebral vasodilatation. Reduction in the MCA pulsatility index after intrathecal midazolam therapy suggests that vasospasm in MCA is alleviated.

Regarding PI and RI they were of great value in both correlation and prediction of neuronal complications (PRESS, eclampsia). Intrathecl midazolam has dampened the PI value post partum $6 \mathrm{~h}$ and $24 \mathrm{~h}$, this can be attributed to antidoting of GABA mimetic action of intrathecal midazolam against excitatory glutamate. Strong correlation with ischemic infarction and post partum eclampsia was conclusive specifically in PI and RI as they expressed the total vascular resistance of MCA to blood flow.

We reported high predictive value of PI $(>1.3)$ with incidence of eclampsia reached to $>80 \%$. PI changed more than RI with relief of excitatory glutamate and aspartate. PI was more sensitive than RI in both prediction and correlation 
of neuronal complications.

Risk stratification based on serial management by TCD indices concluded that patients with PI (1 - 1.3) at risk of PRESS, PI (1.3 - 1.8) at risk of eclampsia and PI (1.8 - 2.5) at risk of ICH.

In controversy with us, Riskin et al, 2002 studied 166 women in the second trimester of pregnancy to measure peak, end-diastolic, and mean velocities in the middle cerebral arteries. Middle cerebral arteries pulsatility and resistive indices were lower in the women with preeclampsia who were initially normotensive compared with the pregnant women who were normotensive $(0.83$ and 0.54 vs 0.73 and 0.50 , respectively; $\mathrm{P}<0.05$ ). This can be explained by early use of oral antihypertensive drugs (alphamethyldopa) which mediate cerebral vascular vasodilatation.

Preeclamptic patients in both groups have been evaluated with transcranial Doppler ultrasound in the immediate and extended postpartum periods. Williams et al., 2015 investigated 46 preeclamptic women in the antepartum period and again at 24 and 48 hours postpartum. They determined that these patients had elevated systolic, diastolic, and mean velocities in the MCA 24 hours postpartum compared with those in the antenatal period. They also demonstrated a further increase in all velocities at 48 hours postpartum. The same investigators also found that preeclamptic women, compared with normotensive women, had elevated cerebral blood flow velocities in the antepartum period and at 24 and 48 hours postpartum. These data suggest that the cerebral vasculature of preeclamptic women is in a vasoconstricted state before delivery as well as in the immediate postpartum period (i.e., up to 48 hours after delivery) compared with normotensive women.

TCD velocimetry indices were very helpful in prediction and detection of incidence of complications, when regression analysis was done for PI basal, PI 6 hit showed that the most powerful index that can predict complications was PI $\left(R^{2}=0.405\right)$. This means that two indices included can predict $81 \%$ of cases with complications which is highly significant value.

Bivariate correlation revealed significant positive moderate association between PI BASAL, PI $6 \mathrm{hr}$, and presence of complications $(\mathrm{r}=0.526,0.574, \mathrm{P}<0.001)$.

\section{Limitations to Our Study}

There were some limitations to the present study:

1) The difficult transport of patients was the cause of relatively few number of TCD readings of the maternal MCA, for fear of complications.

2) Invasive blood pressure wasn't available in our ICU, so we relied on NIBP on our work that was more sensitive to TCD.

3) Exclusion of end organ failure patients from the study.

\section{Conclusion}

Intrathecal midazolam was safe in severe preeclamptic ladies, did not cause any 
foetal or maternal compromise, and eventually decreased degree of cerebral vasospasm and decreased resistive vascular indices of maternal cerebral artery.

\section{Acknowledgements}

We are grateful to Dr Gehad Fathi, assistant lecturer of anesthesia who helped us in data collection. The authors dive thanks to Department of Obstetrics and Gynecology for their effort and help in lady transfer and fetal monitoring.

\section{Contributions}

Dr Mina M. Raouf had full access to all the data in the study, and takes the responsibility for the integrity of the data and the accuracy of the data analysis.

Dr Hany K. Mikhail designed the study protocol and generated random allocation sequence.

Dr Samar M. Magdy managed the literature searches, clinical cases and wrote the first draft of manuscript.

Dr. Mohammad A. Aminn: pre and postpartum transcranial Doppler via temporal bone.

\section{Financial Support}

This research did not receive any specific grant from funding agencies in the public, commercial, or not-for-profit sectors.

\section{Implication statement}

This prospective study is aiming to ameliorate severe preeclampsia induced neuronal excitation due sympathetic surge reflected on maternal middle cerebral artery resistive vascular indices.

\section{Ethics Approval and Consent to Participate}

The current research is adherent to declaration of Helsinki over ethical committee record 293.9/2019. Written consent was taken from lady herself or next of Kinn, Consent is in Arabic and including agreement for caesarian section and anther one for research participation.

\section{Conflicts of Interest}

The authors declare that they have no competing interests.

\section{References}

[1] Eiland, E., Nzerue, C. and Faulkner, M. (2012) Preeclampsia 2012. Journal of Pregnancy, 2012, Article ID: 586578. https://doi.org/10.1155/2012/586578

[2] Vatten, L.J. and Skjærven, R. (2004) Is Pre-Eclampsia More Than One Disease? BJOG: An International Journal of Obstetrics \& Gynaecology, 111, 298-302. https://doi.org/10.1111/j.1471-0528.2004.00071.x

[3] Ngoc, N.T., Merialdi, M., Abdel-Aleem, H., Carroli, G., Purwar, M., Zavaleta, N., 
Campódonico, L., Ali, M.M., Hofmeyr, G.J., Mathai, M. and Lincetto, O. (2006) Causes of Stillbirths and Early Neonatal Deaths: Data from 7993 Pregnancies in Six Developing Countries. Bulletin of the World Health Organization, 84, 699-705. https://doi.org/10.2471/BLT.05.027300

[4] Arulkumaran, N. and Lightstone, L. (2013) Severe Pre-Eclampsia and Hypertensive Crises. Best Practice \& Research Clinical Obstetrics \& Gynaecology, 27, 877-884. https://doi.org/10.1016/j.bpobgyn.2013.07.003

[5] Garg, A.X., Nevis, I.F., McArthur, E., Sontrop, J.M., Koval, J.J., Lam, N.N., Hildebrand, A.M., Reese, P.P., Storsley, L., Gill, J.S. and Segev, D.L. (2015) Gestational Hypertension and Preeclampsia in Living Kidney Donors. New England Journal of Medicine, 372, 124-133. https://doi.org/10.1056/NEJMoa1408932

[6] Hauser, S., Longo, D.L., Jameson, J.L., Kasper, D.L. and Loscalzo, J. (2012) Harrison's Principles of Internal Medicine. McGraw-Hill Companies, Incorporated, 55-61.

[7] Brigo, F., Nardone, R., Tezzon, F. and Trinka, E. (2015) Nonintravenous Midazolam versus Intravenous or Rectal Diazepam for the Treatment of Early Status Epilepticus: A Systematic Review with Meta-Analysis. Epilepsy \& Behavior, 49, 325-336. https://doi.org/10.1016/j.yebeh.2015.02.030

[8] Bohlhalter, S., Weinmann, O., Mohler, H. and Fritschy, J.M. (1996) Laminar Compartmentalization of GABAA-Receptor Subtypes in the Spinal Cord: An Immunohistochemical Study. Journal of Neuroscience, 16, 283-297. https://doi.org/10.1523/JNEUROSCI.16-01-00283.1996

[9] Williams, K. and Galerneau, F. (2003) Maternal Transcranial Doppler in Pre-Eclampsia and Eclampsia. Ultrasound in Obstetrics and Gynecology: The Official Journal of the International Society of Ultrasound in Obstetrics and Gynecology, 21, 507-513. https://doi.org/10.1002/uog.83

$\begin{array}{ll}\text { Abbreviations } \\ \text { DBP } & \text { Diastolic blood pressure } \\ \text { CT } & \text { Computerized tomography } \\ \text { CTG } & \text { Cardiotocography } \\ \text { NIBP } & \text { non invasive blood pressure } \\ \text { MAP } & \text { Mean arterial blood pressure } \\ \text { MFV } & \text { Mean flow velocity } \\ \text { SBP } & \text { Systolic blood pressure } \\ \text { PI } & \text { Pulsatility index } \\ \text { RI } & \text { Resistive index }\end{array}$

